\title{
How Does U.S Governmental Policy Impact Opioid Treatment?
}

\author{
Clairmont Griffith and Bernice La France*
}

Howard University College of Medicine, 520 W St, NW, Washington, DC 20059, USA

*Corresponding author: Bernice La France, Howard University College of Medicine, 520 W St, NW, Washington, DC 20059, USA, Tel: +1

202 8656714; E-mail: bemore1576@gmail.com

Received date: Aug 26, 2018; Accepted date: Oct 15, 2018; Published date: Oct 22, 2018

Citation: Griffith C, France BL (2018) How Does U.S Governmental Policy Impact Opioid Treatment?. Int J Appl Sci Res Rev. Vol.5 No.3: 12.

Copyright: (C) 2018 Griffith C, et al. Th is is an open-access article distributed und er the terms of the Creative Comm ons Attribution License, which permits unrestricted use, distribution, and reproduction in any medium, provided the original author and source are credited.

\section{Abstract}

The purpose of this research article is to examine how the U.S government policy impacts opioid treatment. To understand this, the paper presents a review of the existing literature. Millions of Americans are affected by the opioid crisis, and this leads to the death of more than 35,000 Americans on an annual basis (The President's Commission 2017). The management of the opioid crisis is a major challenge to the U.S government and the department of health. The findings reveal that the government has established several policies to boost the fight against opioids in the country. The government has implemented the use of evidence-based prescription to reduce the misuse and abuse of opioids. The government has also established a recovery support system that has enabled care providers to rehabilitate opioid addicts through medication and behavioural therapies. Therefore, the federal government policies have positively influenced opioid treatment in the US. The policy on adherence to the evidence-based practice of prescribing opioids has a positive impact on the treatment of opioids since it prevents the misuse that leads to overdose and deaths associated with opioids. The policy on increasing the availability of overdose-reversing medication helps in treating individuals who are at risk of overdose from opioids abuse. This effort has been enhanced by another policy, the establishment of recovery support services. The support services have enabled care providers to help opioids addicts to navigate their stages of addiction and attain long-term recoveries successfully. Finally, the federal government's funding of opioid programs also provides relevant resources to enhance the treatment of opioids.

Keywords: Opioid treatment; Opioid crisis; Addiction; Hea Ith policy; Substance use disorder

\section{Introduction}

The objective of this paper is to examine how the existing U.S Federal government policies are impacting the treatment of opioid addiction in the country.

Opioid crisis in the U.S is imputed to the increased prescription of opioids namely heroin and fentanyl among patients in the past two decades. There has been a rise in the large-scale production of pure, effective, and addictive opioids, making these substances readily available for misuse. According to The President's Commission 2017, statistics show that an estimated 92 million U.S citizens were using opioids in the year 2016. Out of this population, 11.5 million citizens were found to be abusing opioids as a pain reliever, and hence, falling into the category of individuals with opioid use disorders (OUD). Recent statistics also show that opioids cause death of an estimated 35,000 Americans on an annual basis, which is higher than the number of deaths caused by gun and road related accidents (The President's Commission 2017). In addition to this, there is an incessant annual increase in the number of U.S citizens who are addicted to opioids. The treatment of opioids is a key challenge to the American government since it is associated with high costs and instances of relapse. Opioid addiction is a complex issue in the U.S health system since it is influenced by many factors such as poverty, lack of treatment, and availability of the opioids (Alexander, Frattaroli, Gielen 2017). Therefore, the key to reducing the number of opioid addiction and opioid overdoserelated deaths is dependent on the implementation of effective opioid policies. Historically, the successful treatment and management of the opioid crisis have been through the implementation of policies such as effective prescription practices, medical education, and effective regulations Alexander et al. In line with these aspects, the government of the U.S has formulated and implemented policies to address the current opioid crisis. These policies have had both positive and negative impacts on the treatment of opioids [1-3]. 


\section{Methodology}

\section{Material and methods}

To achieve the objective of this study, the researcher examined secondary academic sources such as books, Federal and State government reports, and peer-reviewed journal articles. The researcher relied on the information from already published to arrive at a relevant conclusion on how the U.S government policies impact opioid treatment. To collect reliable data from reliable peer-reviewed journal articles, the researcher used medical databases namely, CINAHL, PubMed, ProQuest, and the Cochrane Libraries. Only peer-reviewed sources were used in the study to facilitate reliability Marshall et al. The reliance on secondary sources of information culminates in the use of a systematic literature review as the methodology for data collection and analysis using the following procedure [4-6].

First, the researcher framed a question for review; How Does U.S Governmental Policy Impact Opioid Treatment? Second, the researcher began identifying relevant sources to collect data from. To achieve this, the researcher utilized the question formulated in step 1 above as a guideline on how to identify relevant sources for the study. Here, the researcher identified several keywords, for example, Opioids, Opioid treatment, and Policy on opioids, to facilitate the search process. The researcher used BOOLEAN operators namely AND/OR to combine the keywords during the information search process. The use of BOOLEAN operators was effective in the retrieval of relevant articles. The search terms used in the studies were entered simultaneously. The researcher also utilized MeSH terms related to opioid treatment to adhere to the identified topic of study. The MeSH terms used included Pain Procedural, Mental Status, and Dementia Tests and Patient Health Questionnaire (Morin, Eibl, Franklyn \& Marsh 2017). Treatment adherence and compliance were also used. Third, the researcher assessed the quality of the identified sources to ensure they are reliable. To achieve this, the researcher selected recently published sources, for examples, those that are published within the last five years. The researchers also selected between level II and level III peerreviewed journal articles. Finally, the selected sources were examined and analyzed to identify how they support the topic under study[7-8].

\section{Results}

During the study, the researcher established that the treatment of opioid addiction in the U.S is governed by the Federal Regulation 42 CFR Part 8. This federal regulation provides the guideline for the accreditation and certification opioid treatment system in the country. It also forms the basis for the government policies that affect opioid treatment in the country, and therefore, the following findings were made during the study.

The Federal government has formulated a policy that enhances the adherence to evidence-based practices of prescribing opioids. This has been achieved with the help of the Center for Disease and Prevention (CDC) has established appropriate guidelines for the prescription of opioids for patients with chronic pain (The President's Commission, 2017). This government policy ensures that primary care clinicians prescribe the right amount of opioids for patients who are under palliative care, and hence, minimizes the risk of opioid addiction and overdose.

Another government policy that affects opioid treatment is the expanded access to Medication Assisted Treatment (MAT). This policy provides a comprehensive strategy for providing help to American citizens who are affected by opioid use disorder (Marie, Arnstein, \& Zimmer 2018). It makes use of both behavioural therapies and medication counselling.

The U.S government has increased the availability of overdose-reversing medications in response to the opioid crisis (The President's Commission, 2017). This law has been implemented in all the U.S 50 states, whereby the department of health in these states introduced new laws to allow more supply of overdose-reversing medications such as naloxone (Table 1).

Table 1: The table below summarizes the findings of the study.

\begin{tabular}{|l|l|}
\hline Policy & Effectiveness (100) \\
\hline Adherence to evidence-based practice & $20 \%$ \\
\hline Expanded MAT access & $19 \%$ \\
\hline Increased Availability of over dose medications & $17 \%$ \\
\hline Recovery support services & $20 \%$ \\
\hline
\end{tabular}

Recovery support services is another policy that impacts the treatment of opioids in the US. Owing to the rising abuse, addiction, and deaths related to the misuse of opioids, the government of the U.S now considers recovery as a vital policy that boosts opioid treatment in the country (Reynolds, Causey, McKee, Reinstein \& Muzyk 2017). Federal funding and programs directed at combating opioid crisis is another policy that impacts opioid treatment in the US. The federal government sets aside an estimated \$6 billion for the treatment and management of opioid crisis on an annual basis. The annual budget is used to minimize opioid use and abuse by patients.

\section{Discussion and Conclusion}

The results above are significant in the treatment of opioids in the US. The policy that enhances the adherence to evidence-based practices of prescription is significant since they help in curbing the abuse and overdose from opioids, and hence, it boosts patient safety. Recent research studies show that the current opioid crisis is attributed to the availability of opioids among patients. Clinicians prescribe a lot of opioids for patients, and this encourages abuse and overdose from the substances Franklin et al. Therefore, this policy boosts opioid treatment by enabling evidence-based prescription, appropriate medication and the monitoring of patients. 
MAT has positive impacts on the treatment of opioids since it helps in treating the adverse changes in the brain structure that are caused by opioid addiction. According to Mohlman, Tanzman, Finison, Pinette and Jones 2016, addiction to opioids causes severe adverse changes to the structure of a patient who is diagnosed with opioid abuse disorder. The federal government's policy of expanded access to MAT helps in preventing these adverse structural changes to the brain through the blockage of particular brain receptors. Despite the positive effect that this policy has on boosting opioid treatment, this policy also strains the treatment of opioids. For one to treat patients who are addicted to opioids, the healthcare provider must apply and get a waiver from both the Drug Enforcement Administration (DEA) and the Substance Abuse and Mental Health Services Administration (SAMHSA). This causes a shortage in the number of care providers who can administer MAT to the large population of those affected by the opioid crisis, in rural areas especially.

The policy on the increased availability of overdosereversing medication has contributed positively towards the treatment of addiction among those affected by the opioid crisis. Overdose from opioids is one of the major causes of deaths and other adverse health effects associated with opioid abuse, and therefore, a strategy that can reverse an overdose is a major boost to opioid treatment Morin et al. The policy has allowed healthcare providers to use medications such as naloxone to treat individuals who have overdosed on opioids Franklin et al. This method has also reduced the cost that is associated with the treatment of opioids since naloxone can be given to non-medical experts to help a patient using opioids to recover from an overdose. Besides, this policy has boosted the treatment of patients who are at risk of overdose.

In a tight link to the overdose reversal medication, the establishment of recovery support services is a major boost in opioid treatment. Recovery support services have contributed to the rehabilitation of many opioid addicts Marshall et al. In recovery support services, care providers use behavioral therapies and medications to help opioid addicts to recover from their addiction. These services are effective in enabling an individual to go through addiction successfully and to achieve long-term recovery.

To aid and ensure increased success rates of the above named policies, federal funding for the combat against the opioid crisis is upheld the treatment of opioid addiction is associated with high financial costs, however, this leads to financial strains among low-income earners who are affected by the opioid crisis Marshall et al. It enables the financing of opioid management programs and increases the availability of personnel and medications used in the treatment of opioids. Conclusion
In conclusion, the opioid crisis is attributed to the increase in the use of prescribed use among patients in the U.S. An estimated 95 million Americans use opioids. This contributes to a high rate of addiction, which currently stands at $\mathbf{1 1 . 5}$ million Americans and 35,000 deaths on an annual basis. In response to the opioid crisis in the country, the government of the U.S has formulated and implemented policies to boost the fight against opioid abuse in the country. To explore how government policy impacts opioid treatment, the researcher utilized a systematic review of secondary sources including books and peer-reviewed journals. Key policies that impact opioid treatment include policies that enhance the adherence to evidence-based practices of prescribing opioids. This has enabled care providers to prescribe the right quantity of opioids to patients, and hence, reducing the chances of misuse of opioids. Government funding has been useful in financing programs and making available resources that are used in the treatment of opioids. The policy that makes available the overdose-reversing medications and recovery support systems have been significant in the improved treatment of those affected by the opioid crisis in the U.S.

\section{References}

1. Alexander GC, Frattaroli S, Gielen AC (2017) The opioid epidemic: From evidence to impact. Baltimore, MD: Johns Hopkins Bloomberg School of Public Health.

2. Franklin G, Sabel J, Jones CM, Mai J, Baumgartner C, et al. (2015) A comprehensive approach to address the prescription opioid epidemic in Washington State: milestones and lessons learned. Am J Public Health 105: 463-469.

3. Marie BS, Arnstein P, Zimmer PA (2018) Pain and opioids: Call for policy action. J Nurse Pract 14: 40-44.

4. Marshall BD, Krieger MS, Yedinak JL, Ogera $P$, Banerjee $P$, et al. (2017) Epidemiology of fentanyl-involved drug overdose deaths: a geospatial retrospective study in Rhode Island, USA. Int J Drug Policy 46: 130-135.

5. Mohlman MK, Tanzman B, Finison K, Pinette M, et al. (2016) Impact of medication-assisted treatment for opioid addiction on Medicaid expenditures and health services utilization rates in Vermont. J Subst Abuse Treat 67: 9-14.

6. Morin KA, Eibl JK, Franklyn AM, Marsh DC (2017) The opioid crisis: Past, present and future policy climate in Ontario, Canada. Subst Abuse Treat Prev Policy 12: 45.

7. Reynolds V, Causey H, McKee J, Reinstein V, Muzyk A (2017) The role of pharmacists in the opioid epidemic an examination of pharmacist-focused initiatives across the United States and North Carolina. N C Med J 78: 202-205.

8. The President's Commission (2017) The President's Commission on Combating Drug Addiction and the Opioid Crisis. Pennsylvania, Washington DC: The White House. 